\title{
EFFECT OF POROUS MEDIA PROPERTIES ON TRANSMISSION LOSSES OF A DIESEL PARTICULATE FILTER UNIT
}

\author{
Waleed Momani \\ Department of Mechanical Engineering, Faculty of Engineering Technology, \\ PO Box 15008, E-mail: momaniwaleed@yahoo.com Al Balqa' Applied \\ University, Amman - Jordan
}

(Received April 15, 2008 Accepted June 2, 2008)

\begin{abstract}
Effect of porous media properties on the sound propagation and transmission losses through such materials and consequently on the noise reduction facto has been studied with the application to diesel particulate filters. Many types of porous diesel particulate filters with different properties and specifications are studied and compared to verify their ability in transmission losses and noise reduction on the exhaust pipe system. It is found that the engineering geometry of diesel particulate filter and porous media properties such as channel width, porous porosity, wall thickness, number of channels and the pressure drop through the porous media has a significant effect on the transmission losses.
\end{abstract}

KEYWORDS: transmission losses, porosity, permeability, pressure drop, diesel particulate filters.

\section{INTRODUCTION}

Porous media properties are varying from one porous to another. Some of these are affecting both of the behavior of the diesel particulate filter (DPF) unit and consequently affecting its transmission losses (TL).

Porous media porosity is defined as the ratio of the pore volume $V_{p}$ to the total volume $V_{t}$ of the body considered. The solid volume $V_{s}$ is given by $V_{s}=V_{t}-V_{p}$. Hence, it suffices to measure two of these three parameters to calculate porosity. Porosity plays an important role in metallic, plastic and enamel coatings, where its presence is definitely important. There are two kinds of porosity of the medium; defined as the three-dimensional porosity, $\phi$, and the two-dimensional porosity, $\phi_{\mathrm{A}}$. Both quantities can be given as:

$$
\begin{aligned}
& \phi=\frac{\text { void volume }}{\text { bulk volume }} \\
& \phi_{A}=\frac{\text { cross - sectional void area }}{\text { total cross - sectional area }}
\end{aligned}
$$

Hence, the void volume of the porous medium can be given as

$$
\text { void volume }=\frac{\phi}{1-\phi}(\text { volume of particles })
$$


Porous media permeability is the term used for the conductivity of the porous medium with respect to permeation by a Newtonian fluid. Permeability, used in this general sense, is of limited usefulness because its value in the same porous sample may vary with the properties of the permeating fluid and the mechanism of permeation. It is more useful and more scientific to separate out the parameters which measure the contribution of the porous medium to the conductivity and are independent of fluid properties and flow mechanisms. This quantity is called the "specific permeability" $\sigma$, or it is just called "permeability", its value is uniquely determined by the pore structure, $[12,13]$

The porosity can often be considered as constant for the whole medium. Since the permeability $\sigma$ describes the ability of the fluid to flow through the porous medium, $\sigma$ is often called the absolute permeability and its quantity depends only on the geometry of the medium. There has been much effort to establish relations between the permeability and the porosity. The permeability is found to be proportional to $\phi^{\mathrm{m}}$ where $m$ is in the range of 3 to 6 depending on the geometry of the medium. The fluid flowing in the pore space is characterized by the dynamic viscosity $\mu$. The viscosity indicates the resistance of the fluid due to shear and angular deformations. At the microscopic level, there are friction forces in the fluid caused by the interchange of momentum in the collisions between the molecules. The strength of the friction forces sets the viscosity of the fluid. Another expression for the viscosity, which is often used, is the kinematics viscosity $v$ defined as $v=\mu / \rho$, where $\rho$ is the density of the fluid. Moreover, the viscosity of incompressible Newtonian fluids (which will be the case of interest here) is assumed to be isotropic; thus, such fluids are characterized by only one viscosity coefficient $\mu,[10]$.

\section{Pore Structure}

Pores are invisible to the naked eye in the majority of porous media. The porous nature of a material is usually established by performing any one of a number of experiments on a sample and observing its behavior, because porous materials behave differently from nonporous ones in a number of respects.

\section{Capillarity in Porous Media}

In a "capillary system", the surfaces separating the various bulk phases play a significant role in determining the physical-chemical state of the system. According to this definition, capillary systems form the vast majority of porous media. In the case of capillary systems, mechanical equilibrium, i.e., the absence of net mechanical forces acting on the system is determined not only by the hydrostatic pressure and gravitational attraction but also by forces associated with surface ension, [12].

\section{Flow through Porous Media}

In this work, the coupled steady state axial mean laminar flows of incompressible viscous Newtonian fluids in porous media are discussed. The flow in the pure fluid region is usually described by the Navier-Stokes system of equations. The most 
popular models for the flow in the porous media are those suggested by Darcy and by Brinkman. The flow of several components and several phases through a porous medium is generally described by introducing macroscopic mass-balance equations in the form of generalized dispersion equations. A porous medium consists of a matrix with a large number of microscopic pores and throats which are typically narrow tubes through which fluid can pass. Soil and sand are both examples of porous media, and the fluid flow in a porous medium can be considered as pouring a cup of water over the soil and letting the water flow into the soil due to the gravitational forces. The description of flow in a porous medium is extremely difficult because of the complexity of the medium. Even though flow in a single tube is given by simple equations, the network of the tubes is impossible to know in detail. Fluid flow through a porous medium is often given by the phenomenological Darcy equation. Consider a porous medium of absolute permeability $\sigma$ in a homogeneous gravitation field, where one fluid of viscosity $\mu$ is injected though the medium by applying a pressure gradient $\Delta P$ across the matrix. Then, the flow rate $Q$ of the fluid through the medium is given by the Darcy's equation, such that:

$$
Q=-\left(\frac{\sigma A}{\mu}\right)\left(\frac{\Delta P}{L}\right)
$$

This is a linear law, similar to the Newton's law of viscosity, Ohm's law of electricity... etc. In equation (3), $Q$ is the volumetric flow rate (or "discharge"), $A$ the normal cross-sectional area of the sample, $L$ the length of the sample in the macroscopic flow direction and $P$ the "piezometric pressure, [13].

Using equation (3), it is possible to determine the permeability $(\sigma)$ of the porous medium. Darcy's equation is applied for those porous media which have regions with smaller pores and are also treated as permeable medium as in the case presented (partially porous medium, not highly porous).The most general equation which describes the matching of boundary conditions at an interface between the larger pores and the permeable medium is the Brinkman's equation, such that:

$$
\Delta P=-\frac{\mu}{\sigma} V+\mu_{e} \nabla^{2} V
$$

where $V$ is the fluid velocity; $\mu$ is the fluid viscosity; $\mu_{e}$ is the effective fluid viscosity.; $\sigma$ is the permeability, and $\Delta P$ is the pressure drop.

The equation satisfied two boundary conditions at the pore-permeable medium interface, which are continuity of the fluid velocity and the shear stress.

Although liquids display a permeability that depends only on the medium, gases display a permeability that depends also on the identity of the gas and the pressure difference across the medium. This variation with the identity and pressure of the gas is known as the slippage. This effect was originally detected with gas flow through capillary tubes, and becomes more pronounced when the diameter of the capillary tube approaches the mean free path of the gas molecule. The mean free path is a function of the molecular weight and kinetic energy of a gas.

Flow in porous media requires the description of both the medium and the flow. In the broadest sense an open pipe is a limited case of a porous medium. Usually, the number of holes or pores is sufficiently large so that a volume average is needed to 
calculate pertinent properties. Pores which occupy a definite fraction of the bulk volume form a complex network of voids.

Flow in a porous medium is usually a creeping flow, where the modified Reynold's number defined for a porous medium is less than one. In order to define the Reynold's number for flow in porous media, the concept of hydraulic radius, $R_{H}$, can be used. The hydraulic radius is defined as the void volume of a porous medium divided by the surface area of the medium, such that

$$
R_{H}=\frac{\text { void volume of porous medium }}{\text { surface area of porous medium }}
$$

If $V_{P}$ : is the particle volume, and $S_{P}$ the surface area of the particle, then for spherical particles, the specific surface, $B$, (which has the dimension of $\mathrm{m}^{-1}$ ) can be defined as:

$$
B=\frac{6}{D}=\frac{S_{P}}{V_{P}}
$$

where $D$ is the particle diameter.

The hydraulic radius can be rewritten in terms of the porosity, $\phi$, the number of particles, $N$, the volume of the particles, $V_{P}$, and the surface area of a particle, $S_{P}$, in the following way:

$$
R_{H}=\frac{\phi V_{P}(N / 1-\phi)}{S_{P} N}=\frac{\phi V_{P}}{S_{P}(1-\phi)}
$$

For nonspherical particles, an effective particle diameter, $D_{P}$, can be defined as:

$$
D_{P}=\frac{6}{B}
$$

The discharge velocity, $\overline{\mathrm{u}}$, and the pore velocity, $v$, (as shown in Figure (1)) are obtained from the mass balance as in the following equation:

$$
\bar{u} A_{t o t}=v A_{\text {void }}
$$

This gives the result:

$$
\bar{u}=\phi_{A} v
$$

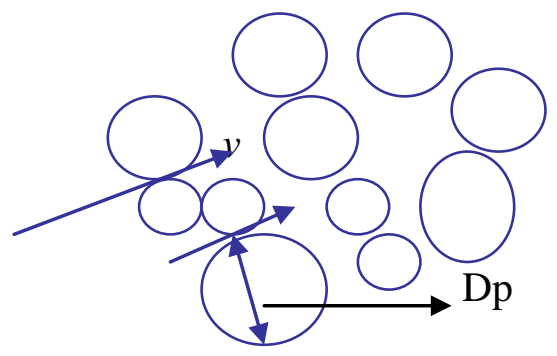

Fig. (1): Velocity of particles during flow through a porous medium. 
Hence Reynold's number for flow in a pipe is:

$$
\begin{aligned}
\operatorname{Re} & =\frac{\rho \bar{u}^{2}}{\mu(\bar{u} / D)} \\
& =\frac{\bar{u} D \rho}{\mu}
\end{aligned}
$$

Where $\mu$ is the viscosity; $\overline{\mathrm{u}}$ is the discharge velocity; $\rho$ is the density of the fluid; $D$ is the diameter of a pipe; and $v$ is the pore velocity $(\mathrm{m} / \mathrm{s})$.

For porous media, the length scale corresponds to the hydraulic radius, $R_{H}$, while the velocity scale is the discharge velocity $\overline{\mathrm{u}}$, divided by the porosity $\phi$.

For the convenience of the definition, the numerical constants are usually dropped and in some definitions the $(1-\phi)$ term is also dropped. The Reynold's number then becomes:

$$
\operatorname{Re}_{P}=\frac{D_{P} \bar{u} \rho}{\mu}
$$

For the case of porous media used in this study, which represents the DPF and the flow which is represented here by the exhaust gas emission having the following properties $\left(\overline{\mathrm{u}}=8 \mathrm{~m} / \mathrm{s}, \rho_{\mathrm{g}}=0.35 \mathrm{~kg} / \mathrm{m}^{3}, \phi=0.337, \mu=4.15 \mathrm{E}^{-5} \mathrm{~N} . \mathrm{s} / \mathrm{m}^{2}\right.$ and $\left.\mathrm{D}=5 \mathrm{E}^{-6} \mathrm{~m}\right)$, and by applying equation (12) yields that: $R e=0.408$, but at low temperatures the exhaust gases' properties are changed.

This result means that Darcy's law is applied for the case of flow in this type of porous media and that the flow is laminar.

\section{Transmission Losses (TL)}

Transmission losses are defined as the difference between the sound power incident on the DPF unit and that transmitted downstream into an anechoic termination. It can be given as:

$$
T L=10 \log \left(W_{i} / W_{t}\right)
$$

where $W_{i}$ is the incident power in watts. $W_{t}$ : is the transmitted power in watts.

For a DPF unit, transmission losses can be given as:

$$
T L=20 \log \left(0.5\left|T_{D P F}\right|\right)
$$

where $\mathrm{T}_{\mathrm{DPF}}$ is the transformation matrix of the DPF unit, [1].

\section{RESULTS, DISCUSSION AND CONCLUSIONS}

As previously mentioned the properties of porous media have significant effects on the flow of fluids through them like fluids, gases and of course the sound propagation. The following results will reveal these effects on sound transmission losses and noise reduction factor for some types of DPF units.

Figure (1) relates TL to channel width of the DPF unit for the case of harmony in time and in 2-D space (under hot conditions). It can be noticed that as the channel 
width increases the TL decreases, because the space inside the DPF unit becomes larger, so sound absorption by channels decreases and hence TL decreases.

Figures (2) and (3) relate TL to permeability of the DPF unit in both cases of time harmonic variation only (under hot conditions) and the case of harmony in time and for 2-D space ( under hot conditions, $\mathrm{w}=700 \mathrm{~Hz}$ ), respectively. It can be noticed that as the permeability increases the TL decreases, because as the permeability increases sound absorption by walls between channels decreases.

Figure (4), which relates TL to wall thickness, shows that as the wall thickness of the channel increases TL increases, because the filter becomes more solid and hence it absorbs or prevents more sound waves causing TL to increase.

Figure (5) represents the relation between pressure drop along the typical DPF unit and the axial velocity. It can be noticed that as the velocity increases the pressure drop also increase. At the same time, as the pressure drop increases TL for the typical filter decreases, as shown in Figure (6). The reason beyond this is that as the pressure drop increases (hence velocity of gases' emission flow increases) time for flow to go through the porous walls decreases, so TL decreases.

Figures (7) and (8) represent the relation between TL and the number of channels per square meter at no soot layer, under hot conditions $(w=700 \mathrm{~Hz})$, for the case of harmony in time and in 2-D space and for time harmonic variation only, respectively. From the last two figures, it can be seen that TL decreases as channels $/ \mathrm{m}^{2}$ increases, because as the number of channels increases the DPF becomes as a hollow cylinder and so noise reduction becomes less, so TL decreases. At the same time, as the number of channels increases, the DPF unit porosity also increases and so TL will decrease as shown in Figure (9).

The main conclusions of this work can be summarized as follows:

- Transmission losses are proportional to frequency, and wall thickness.

- Transmission losses are not proportional to porosity, number of channels per square meter, pressure drop, permeability, and channel width.

- The temperature has a significant effect on both transmission losses and noise reduction factor, as the temperature increase both of these quantities increase. 


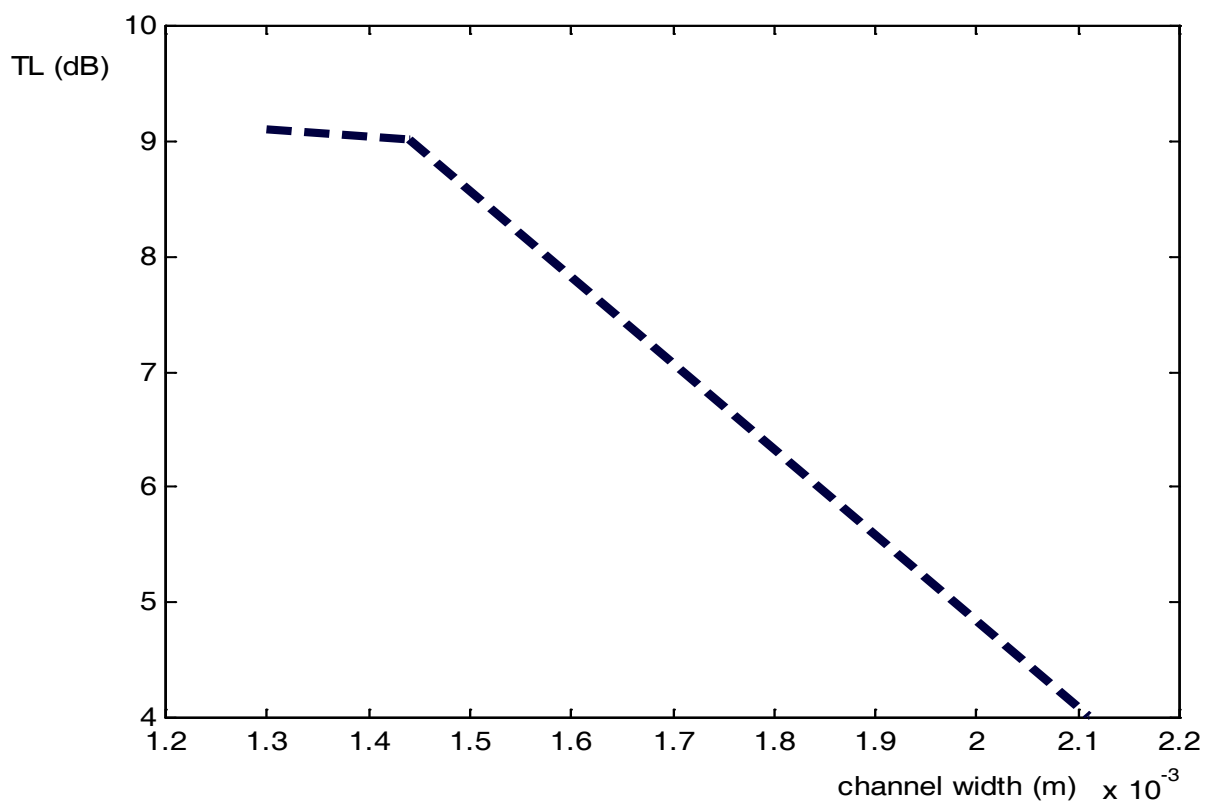

Figure (1): TL against channel width at $\mathrm{w}=700 \mathrm{~Hz}$, with soot layer, harmonic in time and 2-D space case, and under hot conditions.

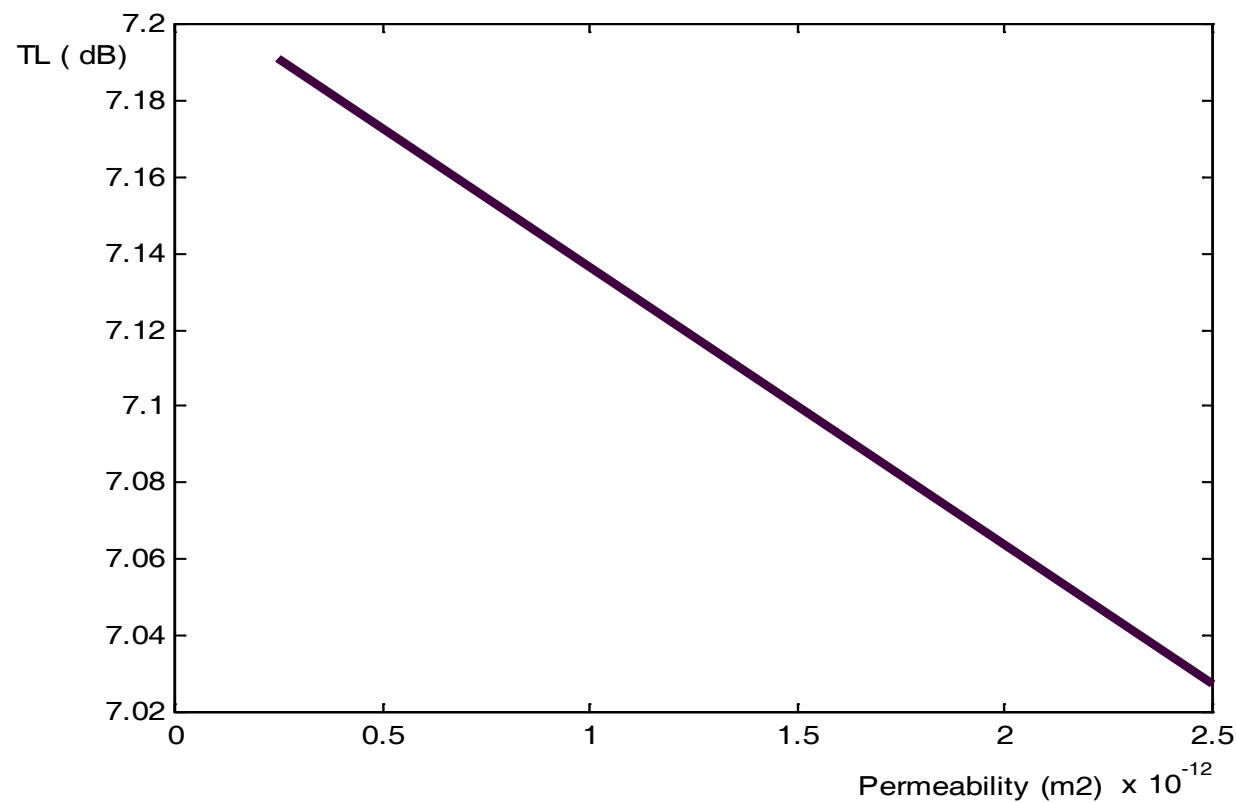

Figure (2): TL against permeability at $\mathrm{w}=700 \mathrm{~Hz}$, with no soot layer, time harmonic variation, and under hot conditions. 


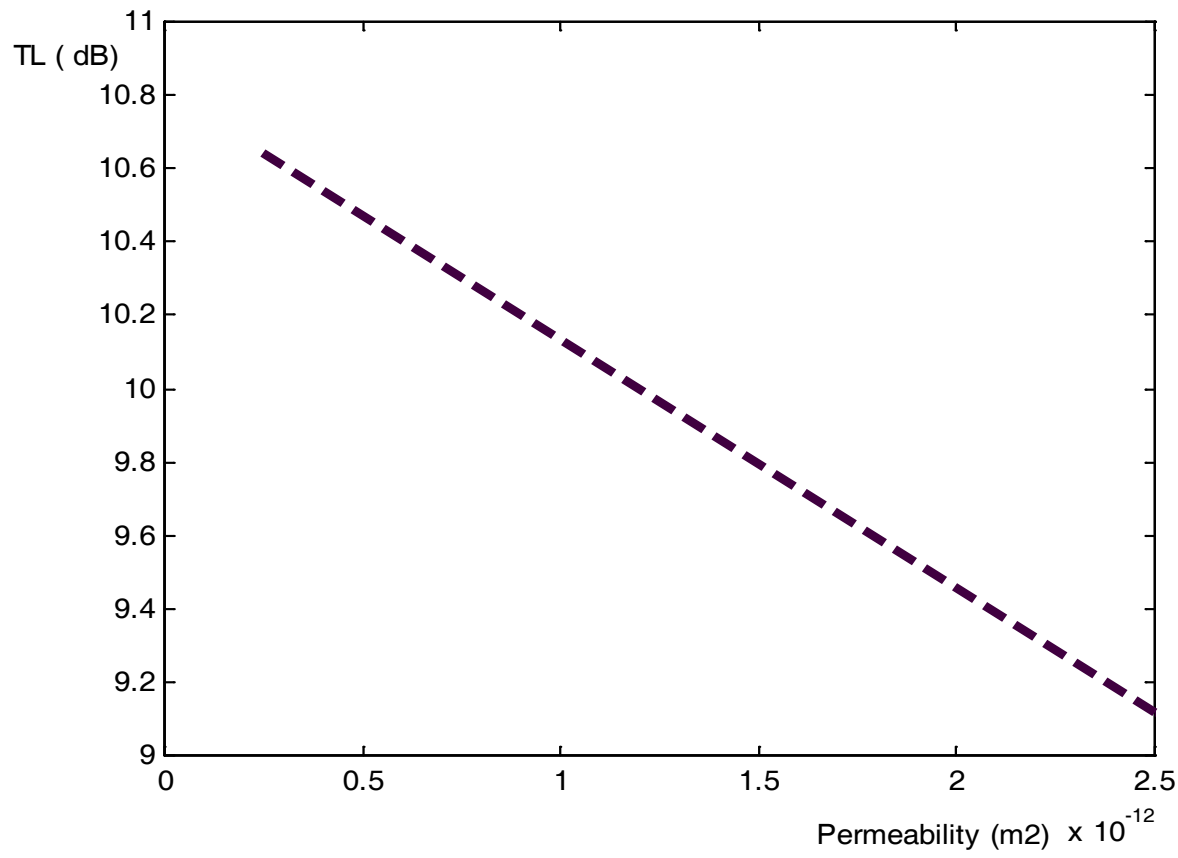

Figure (3): TL against permeability at $\mathrm{w}=700 \mathrm{~Hz}$, with no soot layer, harmonic in time and 2-D space case, and under hot conditions.

$\left(\mathrm{m}^{2}\right)$

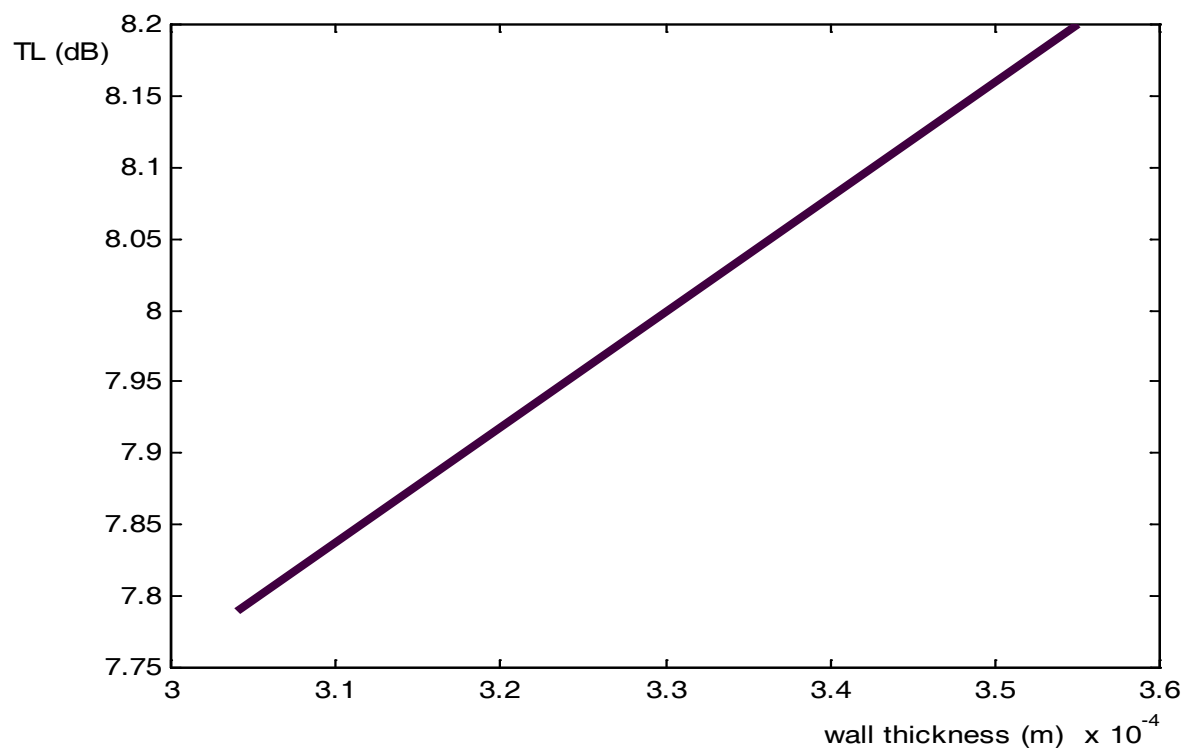

Figure (4): TL against Wall thickness at $w=700 \mathrm{~Hz}$, with no soot layer, time harmonic variation, and under hot conditions. 


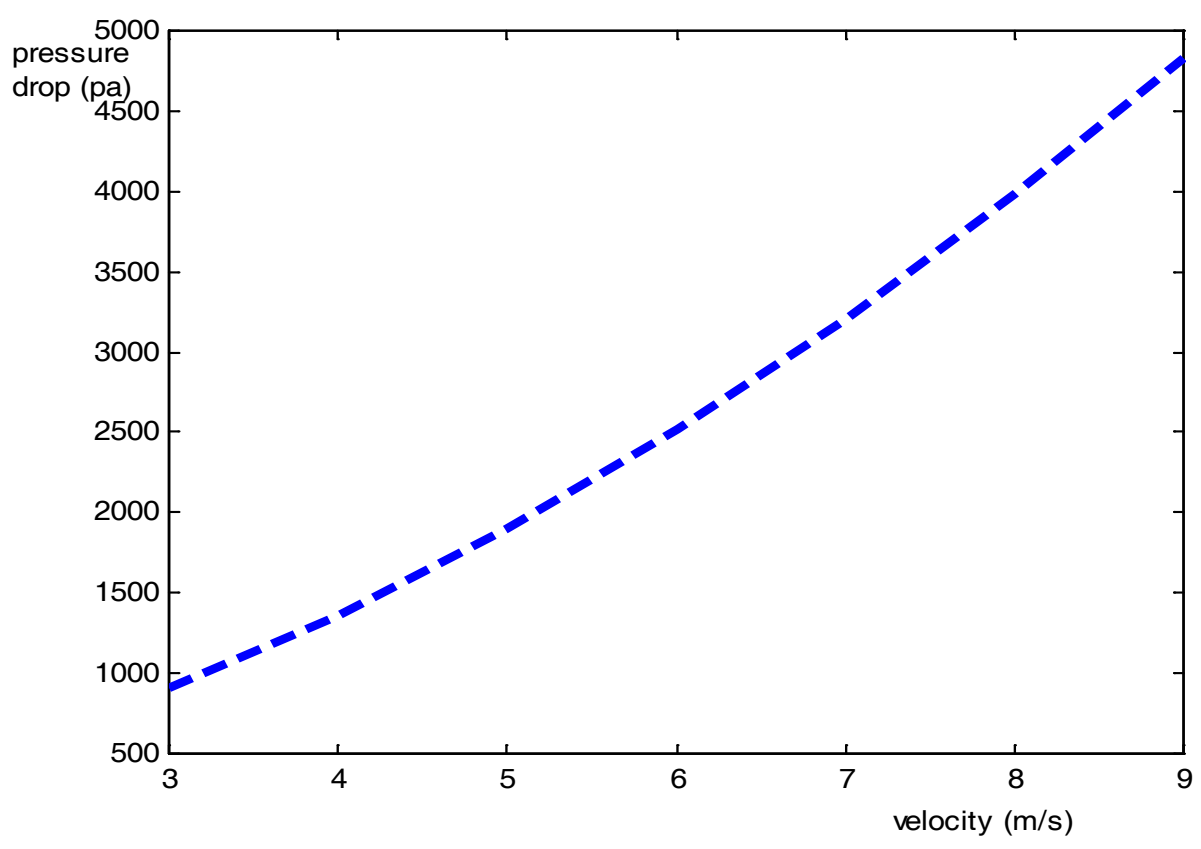

Figure (5): pressure drop against axial velocity for typical filter

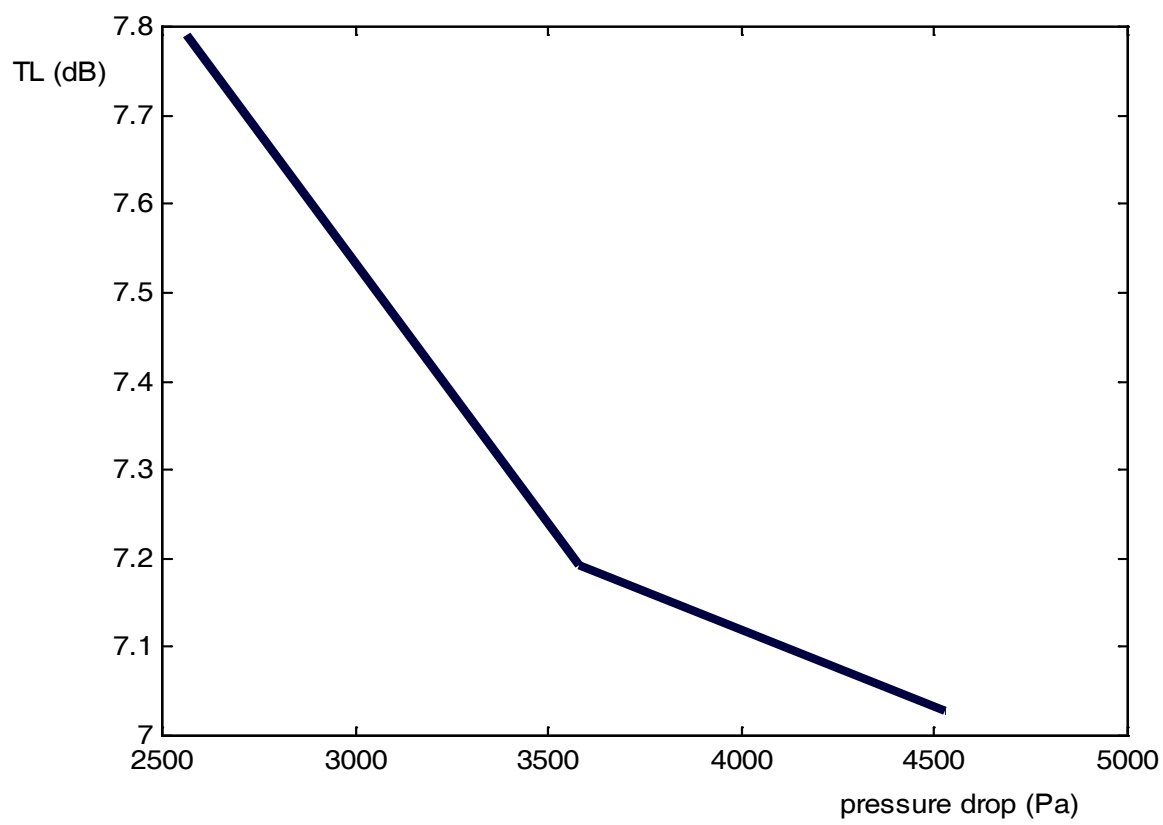

Figure (6): TL against Pressure drop at $\mathrm{w}=700 \mathrm{~Hz}$, with no soot layer, time variation, and under hot conditions. 


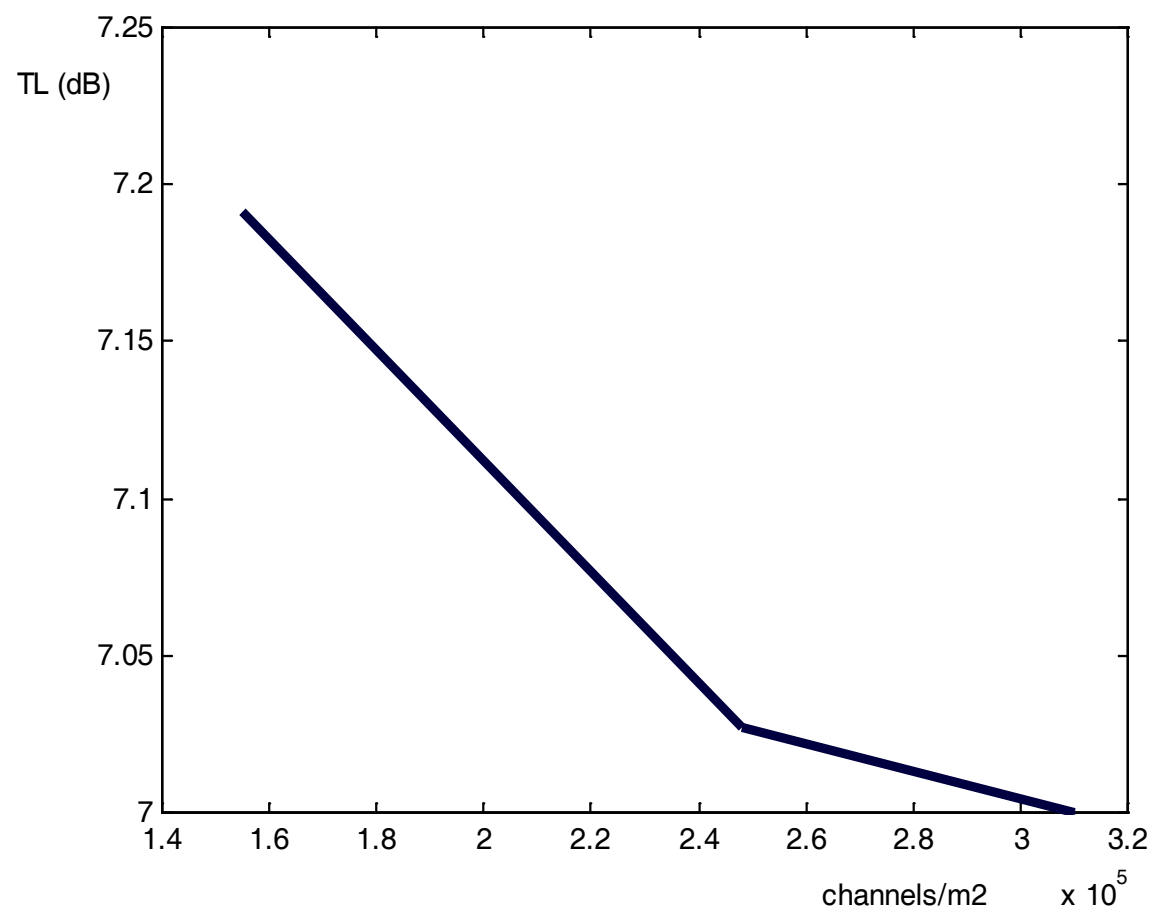

Figure (7): TL against number of channel $/ \mathrm{m}^{2}$ at $\mathrm{w}=700 \mathrm{~Hz}$, with no soot layer, harmonic in time and 2-D space case, and under hot Channels No. $/ \mathrm{m}^{2}$

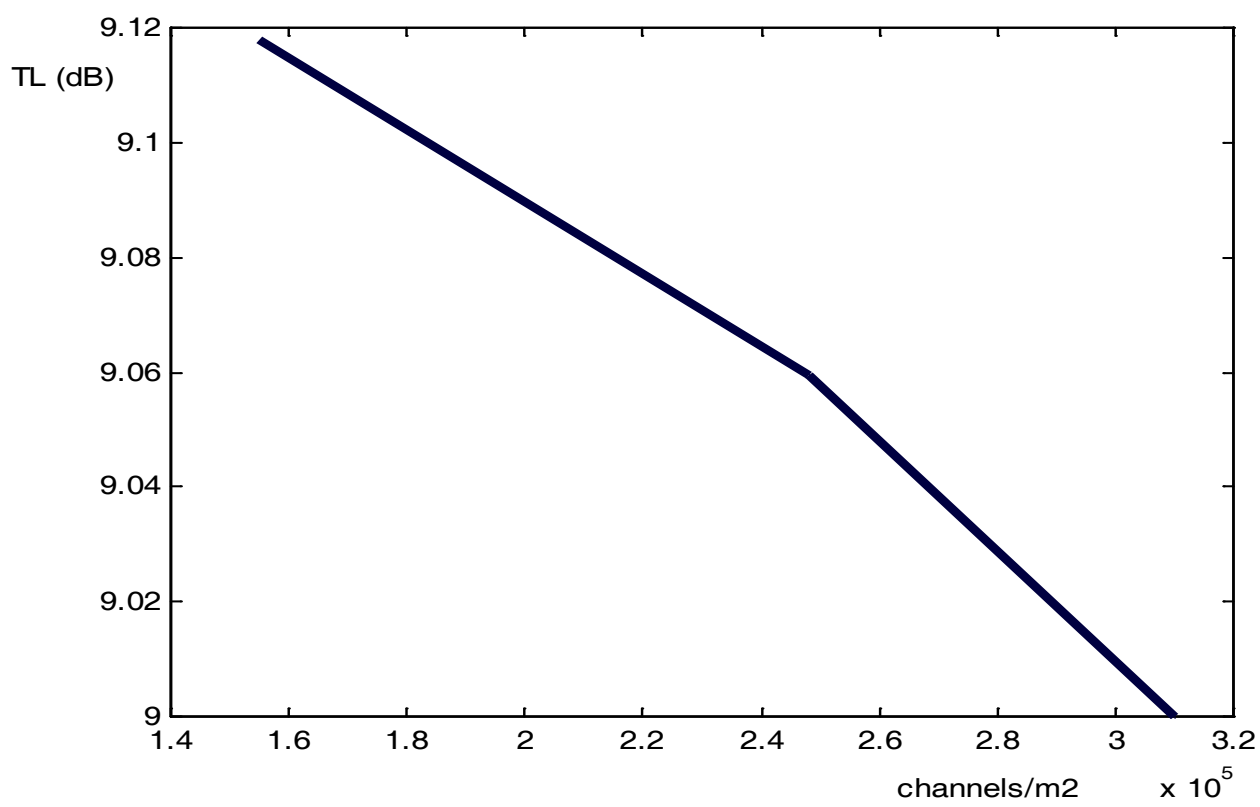

Figure (8): TL against number of channel $/ \mathrm{m}^{2}$ at $\mathrm{w}=700 \mathrm{~Hz}$, with no soot layer, time variation, and under hot conditions.

Channels No. $/ \mathrm{m}^{2}$ 


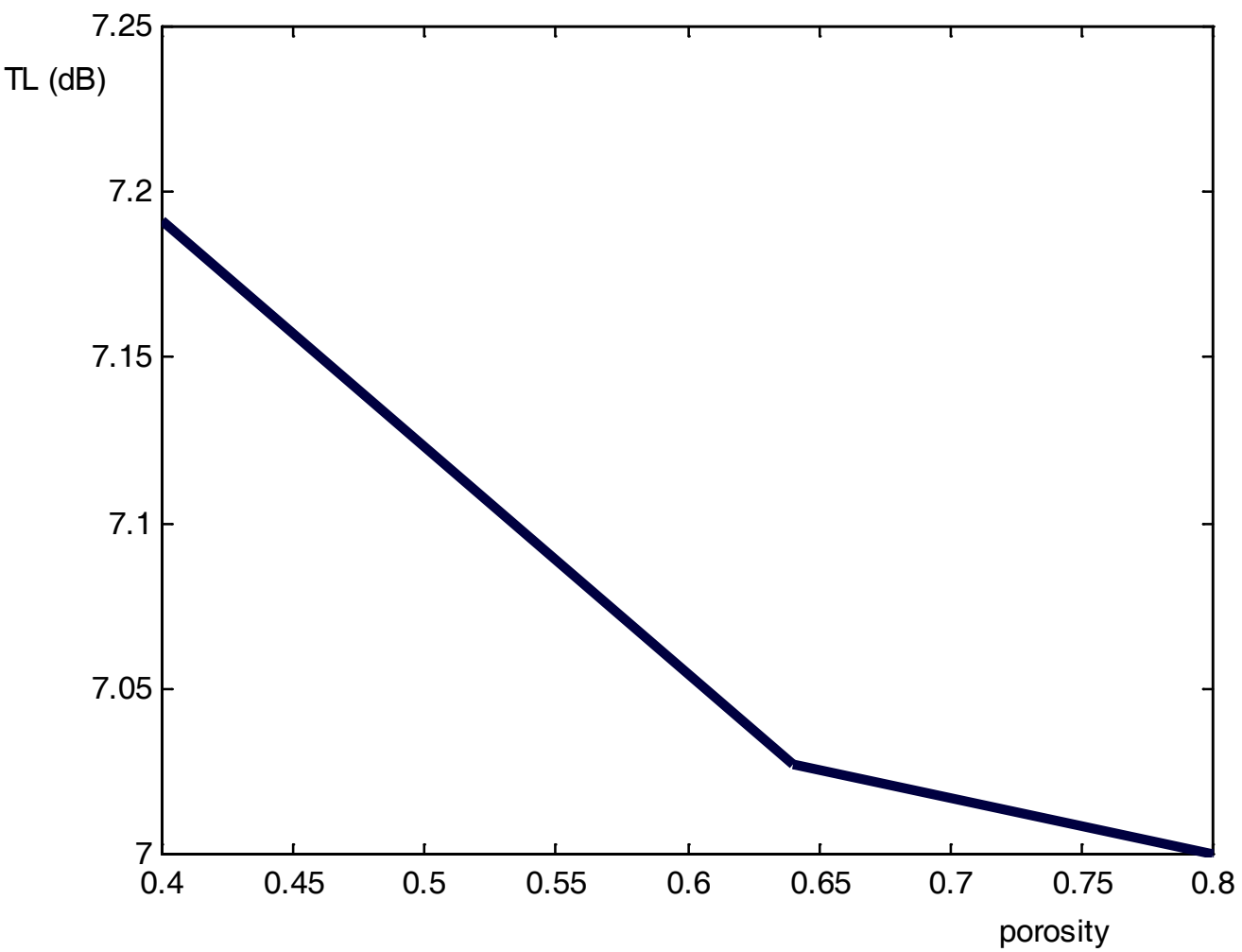

Figure (9): TL against porosity at $\mathrm{w}=700 \mathrm{~Hz}$, with no soot layer, time variation, and under hot conditions.

\section{REFERENCES}

1. Allam, S. and Abom, M. (2006). Sound propagation in an array of narrow porous channels with application to diesel particulate filters, Journal of Sound and Vibration, 291(3-5), 882-901.

2. Arenans, J., Gerges, S., Vergara, E., and Aguayo, J. (2004). On the technique for measuring muffling devices with flow. Acustica 2004, paper ID: 98/P.1. Brazil.

3. Astley, and Cummings, R.A. (1995).Wave propagation in catalytic converter: formulation of the problem and finite element scheme, Journal of Sound and vibration 188 (5), 635-657.

4. Boden, H., and Abom, M. (1995). Maximum sound power from in-duct sources with applications to fans. Journal of Sound and vibration, 187 (3), 543--550.

5. Boden, H., and Abom, M. (1990). Characteristics of acoustic two-port sources. Proceedings- international conference of noise control engineering, p 541.

6. Boden, H., Abom, M., and Glav, R. (1988). Acoustic model for automobile catalytic converters. Proceedings- international conference of noise control engineering, $\mathrm{p} 1261$.

7. Boij, S., and Nilsson, B. (2001). Reflection of sound at area expansion in a flow duct. Journal of Sound and Vibration 260, 477-498. 
8. Cummings, A. (1993). Sound propagation in narrow tubes of arbitrary crosssection. Journal of Sound and Vibration 162 (1), 27-42.

9. Chen, M., and Karen, S. (2003). A modeling approach to the design optimization of catalytic converters of I.C. engines. ASME, ICEF03.

10. Davies, P.O. (1988). Practical flow duct acoustics, Journal of Sound and Vibration 124, 91-115.

11. De Wiest, R.J.M. (1969). Flow through porous media, Academic Press, INC, New York, USA.

12. Fairbrother, R., and Tonsa, M. (2003). Acoustic simulation of after treatment devices using linear and nonlinear methods. Tenth international sound and vibration, 7-10 July 2003, Stockholm, Sweden.

13. Holzbecher, E.O. (1998). Modeling density-driven flow in porous media. Springer-verlag Berlin, Germany.

14. Seto, W. W. (1971). Schaum's outline of theory and problems of acoustics, Schaum's outline series, McGraw-hill book company, USA.

15. Stanley, H., Andrade, J., Almeida, M., Mendes, J., Havlin, S., and Suki, B. (1997). Fluid flow through porous media, physical review letters. Vol. 79, 2.

\section{تأثير خواص المواد المسامية على مقار الإزعاج (مرور الصوت) عبر فلتر ديزل حبيبي(DPF)}

إن لخواص المواد المسامية تأثثر معتبر على انتشار الصوت فيها، ومن ثم تؤثر على مقدار الفقدان في

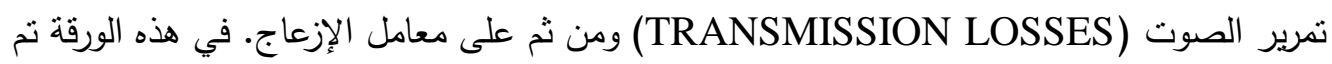

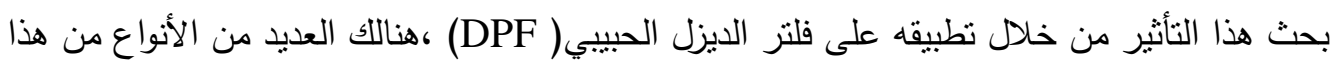

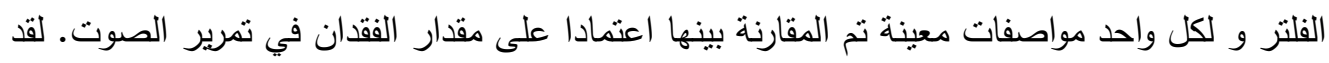

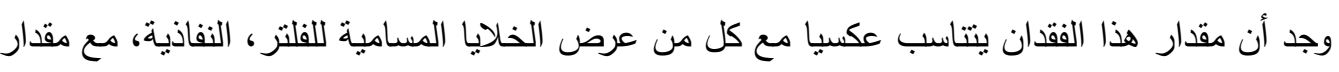

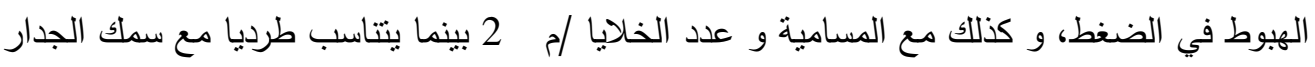

